\title{
REDISCUTINDO CONCEITOS NA ANTROPOLOGIA DA SAÚDE: NOTAS SOBRE OS AGENCIAMENTOS TERAPÊUTICOS
}

Fátima Tavares

Um desafio antigo, mas que vem ganhando novos contornos na prática antropológica contemporânea diz respeito à problematização das bases conceituais em que se assentam as formas do conhecer antropológico. A crítica a modelos dicotômicos fundamentados em premissas coletivizantes versus individualizantes (que, no limite, assentam-se na ruptura entre linguagem e mundo) vem redefinindo o estatuto dos conceitos no âmbito das ciências sociais. Como sugere Strathern (2006), o conhecimento adquire novos contornos, perseguindo não exatamente uma aproximação com o mundo nos moldes do modelo tecnológico de conhecimento cumulativo, mas sim novas possibilidades de experimentação das condições do pensamento.

As proposições que vêm sendo feitas sugerem um deslocamento das metáforas representacionais para uma pragmática das ontologias ou modos de ser no mundo, levando-nos a uma postura bem mais "cautelosa" diante das nossas possibilidades compreensivas do que costumamos chamar de "alteridades". Nossas estratégias (teóricas e metodológicas) de lidarmos com a diferença e a alteridade - centrais na antropologia - passam por experimentos que procuram desafiar os limites das nossas alegorias delineadas na proeminência da substância por contraste com a relação. Perseguindo essas possibilidades, outras percepções da diversidade podem ser aventadas, assim como da "relação", atualizando as diferenças em formas intensiva e extensiva, enviando sempre a formas distintas(assimétricas) de construir diferenças (Viveiros de Castro 2007). ${ }^{1}$ Nesta perspectiva, não há "entidades" a priori, nem "relação" como consequência, nem totalidades sistemáticas ou tipológicas: há relações que fazem fazer, ou seja, não relações entre unidades que constroem semelhanças ou oposições, mas "devires" como pontos de fuga possíveis.

Mas como podemos empreender traduções conceituais das experiências em sua diferença e alteridade por meio, ao mesmo tempo, dos nossos e de novos conceitos? Seria necessário não mais pensarmos em termos dos nossos 
conceitos para produzir interpretações, mas, no contexto dessa "conversa", procurar "traduzi-la nos termos gerais da outra parte" (Viveiros de Castro 2002:138)? É com essa inspiração que busco algumas problematizações na investigação dos processos de cura na contemporaneidade a partir do argumento de que os modelos ancorados em dicotomias e classificações que apressadamente delimitam conceitos como corpo, sujeito e experiência pouco auxiliam na investigação das mediações mobilizadas nas experimentações terapêuticas. Para isso, começo apresentando alguns dilemas em torno da própria constituição do objeto da antropologia da saúde (ou antropologia médica), nas "escolhas" terapêuticas em situações etnográficas de populações indígenas e contextos de adesão religiosa; passando, a seguir, pela crítica a alguns conceitos-chave da antropologia da saúde, para, ao final, propor o conceito de agenciamento terapêutico como abordagem alternativa às discussões sobre itinerário e experiência terapêuticos.

A discussão conceitual sobre agenciamento terapêutico é demarcada por algumas situações etnográficas de minha pesquisa realizada no âmbito da Estratégia Saúde da Família $(E S F)^{2}$ em Juiz de Fora, cidade mineira de médio porte. Considerando a viabilidade da perspectiva de rede desenvolvida por Latour, discuto as mediações que são produzidas nas trajetórias terapêuticas, possibilitando, assim, a investigação do trabalho dos mediadores (humanos e não humanos) aí envolvidos.

\section{Conceituando objetos: corpos, saúde e doença}

Até onde é possível falar sobre processos de saúde e doença sem incorrer em análises que trancafiam os corpos em dimensões previamente reconhecíveis, sem que possamos entrever outras possibilidades de conceituação (Latour 2008)? As descrições antropológicas dos processos terapêuticos devem se valer positivamente das fricções com outras epistemologias, polinizando a imaginação antropológica e descentrando corpos e sujeitos.

A partir das sugestões de trabalhos sobre populações indígenas da América do Sul podemos extrair algumas advertências importantes dos nossos limites conceituais sobre o que sejam saúde, doença e cura, para serem compreendidos em outras traduções possíveis. Se, para a tradição ocidental, os processos intencionais mobilizados pelos sujeitos na construção de suas identidades implicam uma transformação dos estados de espírito ou mudança de mentalidade, para a filosofia ameríndia tudo se passa ao contrário. Sendo o corpo a condição mesma da existência, sua obsessão é pelas transformações corporais - são aquelas que contam - e não espirituais, 
como no nosso caso (Seeger et al. 1979; Viveiros de Castro 1987, 2008). Outras epistemologias evidenciam, então, outros corpos e outras formas de relação entre corpo, saúde e doença, como no caso Kaxinawá, estudado por McCallum (1998), que aponta para uma compreensão alternativa dos corpos na relação com o "conhecimento". Como sugere a autora, o corpo só pode ser desenvolvido através da mediação do conhecimento, decorrendo daí que os conhecimentos "médicos" sobre saúde e doença só podem ser compreendidos, ou acessados, pela mediação dessas duas categorias.

A relação entre corpo e conhecimento possibilita transgredir nossas percepções entre as dimensões do natural e do que é feito, já que, para os Kaxinawá, as fronteiras do que seriam o corpo biológico, de crescimento "natural", e as intervenções (culturais) sobre ele não fazem sentido. ${ }^{3}$ Ao invés disso, o corpo (no que nós entendemos por sua dimensão biológica) se constitui por uma série de intervenções externas, misturando as dimensões física, mental e emocional. O conhecimento não é algo que se localiza numa parte do corpo (como para nós na consciência, na memória ou nas emoções), mas se dissemina pelo corpo em diferentes órgãos. As diferenças, marcantes, evidenciam que o corpo não "cresce" naturalmente, mas deve ser afetado por processos materiais que produzem múltiplas conexões dos corpos com o mundo. A autora chama a atenção para a importância dessas transformações do conceito no âmbito das epistemologias nativas, no mundo da "natureza humana fabricada", numa citação ao trabalho de Viveiros de Castro (1987).

Para os Kaxinawá, em diferentes momentos da vida podem ser observadas as mediações necessárias à feitura dos corpos: desde a concepção, em que é preciso a continuidade da atividade sexual para "fazer crescer" o corpo do feto, passando pela administração de remédios e de dietas que afetam diretamente esse processo. O conceito de "experiência", que também destoa da percepção ocidental, não implica uma capacidade mental, mas produz efeitos cumulativos no corpo. E o que pode ser compreendido por "conhecimento" é essa experiência radicada materialmente no corpo. Conhecimento através da pele, dos orifícios do corpo, do ouvido, da mão, da visão. Os "corpos que sabem" - expressão que sintetiza os argumentos da autora - são aqueles que conseguem exteriorizar conhecimento nas interações sociais.

Alterações no estado de consciência afetam o "conhecimento" do corpo, fazendo com que a doença e a morte possam ser compreendidas como "estados epistemológicos" diferenciados. Um processo de cura pode ser acionado através dos cantos, em que é possível "refazer" o estado epistemológico "saudável" do corpo. O "corpo que sabe" é também o corpo suscetível a adoecer, na medida em que aprendizado e adoecimento são efeitos possíveis do mesmo processo. Isto é visível no conceito de dau (remédio) que tanto 
pode curar como provocar doenças, poderoso mediador das transformações do conhecimento: "Se saúde é uma correta combinação de conhecimento acumulado e da capacidade de agir socialmente, a doença pode ser compreendida como um distúrbio no poder de conhecimento do corpo" (:235).

A discussão sobre os pressupostos implicados nas nossas ideias de saúde e doença e dos limites da "eficácia simbólica" também constitui o ponto de partida do trabalho de Renshaw (2006) sobre os cantos de cura (sarode) ${ }^{4}$ entre os Ayoreo, povo indígena que vive nas regiões de fronteira entre Bolívia e Paraguai. A diferença entre os cantos de cura ayoreo e o tratamento médico convencional não reside nos critérios de eficácia, já que em ambos os casos os pacientes se sentem melhores e, quando isso não acontece, eles procuram outras possibilidades terapêuticas para a resolução dos problemas sem que isso coloque em dúvida as bases do sistema.

Mas a questão intrigante que o autor apresenta é que atualmente os cantos de cura quase não são mais utilizados, levando os Ayoreo a procurar a medicina ocidental assim que ficam doentes, ainda que essa escolha implique alto custo material. As razões para esse declínio não estariam numa crise da eficácia dessa técnica, mas decorrem de questões "externas" aos procedimentos terapêuticos, acarretando uma reavaliação da legitimidade do "poder" que é invocado nos sarode.

Seria preciso, então, como sugere Renshaw, problematizar a própria pergunta sobre como os sarode produzem seus efeitos curativos. A eficácia dos cantos não reside no sugestionamento alcançado através de metáforas e mitos evocados entre poder animal e a cura (sugerido nas letras dos cantos). É preciso entrar na epistemologia ayoreo: “[...] os cantos de cura são um modo de conhecimento que reproduz o poder do mundo mítico e, de fato, fazem parte de um corpus maior de mito" (2006:416).

Tem-se, assim, uma conceituação dos sarode que não deve ficar restrita à sua "eficácia terapêutica", mas remete ao contexto epistemológico dos Ayoreo, em que se encontra atualmente em questão a legitimidade (mítica) do poder que é invocado nos cantos. Um poder que não é metafórico, mas reside literalmente nos cantos. Não sendo apenas uma técnica de cura, os cantos evidenciam uma teoria do conhecimento ayoreo que está sendo continuamente reavaliada, diferenciando-se do conhecimento ocidental no que diz respeito às suas bases universalistas.

As relações entre corpo e conhecimento entre os Kaxinawá e o poder implicado nos cantos de cura ayoreo são bons indicativos das potencialidades de descrições etnográficas que não delimitam aprioristicamente os contornos do que seriam os processos de cura nas situações de pesquisa. Vêm de McCallum, nesse mesmo trabalho, as preocupações com o descompasso 
entre a literatura etnográfica da Amazônia sobre o corpo ${ }^{5}$ e os interesses da antropologia médica nessa região, que prioriza a investigação das doenças e dos processos de cura e xamanismo. Quais seriam as consequências de uma antropologia do corpo encapsulada nas preocupações com os processos de doença e cura? A via de acesso ao corpo é mais restrita. Sendo investigadas como objeto (no paciente) ou instrumento de cura (corpo do xamã), as questões ontológicas envolvendo o corpo acabam sendo relegadas a segundo plano.

As cautelas na investigação dos processos de cura nos convidam a não empobrecer as diferenças conceituais. Estas se tornam tão mais importantes quando também consideramos as circunstâncias de modernização dos serviços de saúde que incidem sobre essas populações, configurando desafios partilhados tanto pelas etnografias sobre povos tradicionais (indígenas, quilombolas e outros) como as populações carentes rurais e das periferias urbanas do país. Esse é um dilema apontado por Kelly (2005) em trabalho sobre os Yanomami, em que é preciso lidar com as situações modernas sem desconsiderar os tipos de "gente" envolvidos, chamando a atenção para o problema das avaliações apressadas sobre a "perda cultural" entre populações indígenas da Amazônia venezuelana na relação com o sistema de saúde oficial. Como observa o autor, a "pluralidade terapêutica" contemporânea existente nessa região, em que "convivem" sistemas tradicionais com a biomedicina, não pode ofuscar diferenças que estão para além das questões relativas à saúde e à doença.

\section{Experiências e agências terapêutico-religiosas}

Seguindo adiante nesse exercício de problematização, passemos dos conceitos sobre o objeto da antropologia da saúde para a questão dos processos de cura, enfocando especialmente a relação entre experiências do adoecer (dimensões subjetivas e/ou intersubjetivas) e agências terapêuticas (dimensão social). Como argumenta Augé (1984), o paradoxo da doença é que ela é ao mesmo tempo a mais individual e a mais social das coisas. Cada um de nós só pode experimentá-la em seu próprio corpo, mas ao mesmo tempo tudo nela é social, não somente porque um grande número de instituições a tomam como objeto de intervenção em suas diferentes fases de evolução, mas porque os esquemas de seu reconhecimento são sociais: pensar a sua doença é já fazer referência aos outros.

As abordagens dos processos de cura cujo enfoque recai nas agências terapêuticas religiosas tendem a priorizar a investigação dos tratamentos 
disponíveis a partir de suas cosmologias e/ou do grau de legitimidade social de que desfrutam para se compreenderem os processos de "escolha". No caso das terapêuticas religiosas, esse enquadre, bastante recorrente, acaba trazendo alguns problemas. Duas premissas (implícitas) orientam a percepção de que para se compreender a escolha por um tratamento religioso é preciso situá-la em seu referencial cosmológico: (a) a "escolha" implica, em algum grau, uma "adesão" (no limite, uma "conversão") a esse referencial; e (b) a "adesão" funciona como uma espécie de "contexto explicativo" para a compreensão dessa escolha, pois, de outra forma, ela se tornaria incompreensível ou marcada pela irracionalidade. As diferentes cosmologias que orientam os modelos terapêuticos religiosos são muitas vezes compreendidas como universos de significação claramente discerníveis, comportando recursos terapêuticos específicos. No fim das contas, reedita-se um velho modelo: a(s) escolha(s) do(s) tratamento(s) depende(m), fundamentalmente, de disposições culturalmente adquiridas e que devem ser compreendidas no âmbito das representações sociais (e que orientariam as práticas).

Mas quando se trata de investigar o processo de cura enquanto transformação de pessoas, corpos e afetos é preciso problematizar tanto as delimitações de fronteiras identitárias como os sincretismos que as atravessam. Ambas as perspectivas são decorrentes da centralidade conferida às terapêuticas religiosas enquanto agências, tomadas como modelos "fechados" (comportando cosmologias, doutrinas e recursos terapêuticos) e "alternativos" à intervenção terapêutica da biomedicina (Montero 2006).

No que tange à questão previamente levantada, a antropologia da religião pode trazer contribuições importantes para a problematização daquelas categorias. Particularmente a questão da conversão religiosa ajuda na compreensão da relação entre crenças e práticas: as práticas não decorrem de uma reorientação consciente das crenças no "enquadramento" cosmológico oferecido pela nova religião. Observa-se, antes, uma relação dinâmica, conjuntamente articulada, entre esses dois níveis. Na medida em que a conversão implica necessariamente um engajamento corporal, a crença passa a ser compreendida não como um projeto acabado, previamente existente, mas sim como a possibilidade de uma nova forma de ser-no-mundo (Rabelo et al. 2002).

Mas considerar que se devam fazer escolhas entre a ênfase nas representações ou nas práticas revela também as condições nas quais, nós, pesquisadores, temos sido treinados. Esta é a advertência feita por Carozzi (2002), ao enfatizar que o que chamamos de "crenças" e "práticas" religiosas não são mais do que reificações decorrentes das práticas clássicas de investigação a que nos temos habituados. Assim, enfatiza a autora, a separação do discurso 
em relação à ação advém do nosso treinamento escolar, que finca raízes profundas na tradição cristã. No jogo social empreendido pela pesquisa de campo, é considerada uma prática legítima o "isolamento" dos nossos "nativos" do seu ambiente social, produzindo uma interrupção no fluxo de sua vida cotidiana para que se possa elaborar uma narrativa da sua (deles) experiência. Nessas condições, constitui a nossa atitude "natural" (dos pesquisadores) tomar o discurso enquanto crença, fruto do que as pessoas narram no contexto da entrevista, para alçá-lo a uma categoria distinta das demais práticas. A produção do discurso constitui, portanto, uma decorrência de um treinamento que visa identificá-lo em proximidade com o "eu" por oposição à resistência supostamente imprimida pelo hábito corporal:

A habilidade adquirida na escola e nos rituais modernos de produzir discursos sobre discursos e discursos sobre ações raramente é concebida como um hábito corporal, como as características do impulso, disposição afetiva, identificação e poder sobre nós mesmos que os hábitos "do corpo" supõem (Carozzi 2002:8384, tradução minha).

As reificações engendradas no processo da pesquisa, que estabelecem dicotomias entre ação e discurso, práticas e representações, parecem decorrer das nossas diferenças de atenção. Estas tendem, além de separar, a hierarquizar as práticas sociais, de forma a reconhecermos nos discursos emitidos por nossos interlocutores uma dimensão central para a compreensão dos processos observados, tidos como separados da ação, da participação, da experiência e da sensação (Carozzi 2002:87).

É o que também acentua Favret-Saada (2001) quando problematiza as condições de realização da pesquisa antropológica assentada na pressuposição da existência de um discurso neutro sobre o qual poderíamos compreender a diferença. Em sua investigação sobre crenças em bruxaria entre camponeses franceses, ela insiste na inadequação desse conceito para retratar outros mundos possíveis. Mundos onde a linguagem interdita a construção de um enfoque representacional sobre as coisas, mas ela mesma seria compreendida segundo outras condições de possibilidade. Nas palavras da autora: "Ora, a bruxaria é palavra, mas uma palavra que é poder e não saber ou informação" (2001:26, tradução minha). 


\section{Transformações do terapêutico: práticas, representações e itinerários}

O rastro da experiência deixa entrever processos de significação que dificilmente podem ser enquadrados nos limites de modelos preestabelecidos que separam as representações das práticas. A criatividade - no sentido wagneriano (Wagner 2010) - reside justamente na capacidade de "subverter" expectativas, promovendo deslocamentos e metaforizações que estendem as significações para além dos seus domínios convencionais.

É o que se pode observar atualmente com o conceito de "terapêutico". A extensibilidade que essa noção vem adquirindo pode ser compreendida nesta perspectiva (Tavares 2006). O "terapêutico" não se restringe ao conjunto de mediações técnicas que caracterizam os procedimentos e os efeitos mobilizados na cura, sejam eles religiosos ou não (biomedicina, terapêuticas alternativas, religiosas e tradicionais). O "terapêutico" também pode adquirir uma conotação de "valor" que se deseja cultivar mobilizado por meio de um engajamento que compreende uma transformação dos afetos: nesse caso buscam-se os efeitos decorrentes de práticas que, a princípio, não seriam consideradas como terapêuticas (práticas alternativas como a biodança, jogos divinatórios, técnicas de meditação etc.). O seu campo semântico envolve, assim, um leque ampliado de experiências que também podem delinear "estilos" de vida. O mesmo diagnóstico também vale para a proliferação da heterogeneidade dos mediadores aí envolvidos, estendendo-se além das mediações técnicas para incorporar muitos outros humanos e não humanos (Latour 2001).

Para se investigarem os processos terapêuticos (incluindo-se aí suas novas conceituações), deve-se então partir em direção à experiência mobilizada em diferentes situações. No âmbito das ciências sociais, as abordagens iniciais, centradas no comportamento do enfermo, ancoravam-se numa perspectiva voluntarista da ação. Estas foram posteriormente problematizadas através dos estudos de etnomedicina, de minorias culturais (concepções de etiologia e do comportamento do doente), das análises sobre redes sociais e saúde, e do conceito de "sistema de cuidados com a saúde", de Kleinman (1978), numa tentativa de incorporação da dimensão cultural envolvida nesses processos (Alves \& Souza 1999; Langdon 2014).

No campo da antropologia da saúde tem se destacado um conjunto de trabalhos que buscam uma revisão teórico-metodológica, passando por uma ampla crítica às dicotomias conceituais (indivíduo-sociedade; corpo-mente; objetivo-subjetivo), e abrindo a possibilidade para que as abordagens compreensivas (fenomenologia, interacionismo simbólico, etnometodologia) 
ganhem espaço nos estudos (Canesqui 2003). Intensificou-se, assim, a crítica às abordagens "objetivistas", que acabam por "explicar" a diversidade das concepções de doença e seus modos de ação a partir de variáveis sociológicas situadas no âmbito da estrutura social. Nesta perspectiva, ficaria descoberta a compreensão do intrincado processo de significação da experiência do adoecer em sociedades tão heterogêneas como a nossa. Como esclarece Canesqui em análise sobre a produção na área de antropologia da saúde durante os anos de 1990:

Se, por um lado, a abordagem do sujeito ou da ação passou a ser privilegiada, seja na construção da realidade, sempre em busca dos sentidos na intersubjetividade, seja para desprovê-lo de sua automática submissão às estruturas, por outro, buscaram-se mediações entre as estruturas e a ação mediante abordagens que procuram um construtivismo menos radical (2003:111).

No âmbito da perspectiva fenomenológica, alguns estudos procuram atentar para os processos pelos quais as significações da saúde e da doença são elaboradas pelos agentes, rompendo com a dicotomia entre significados culturais (já dados, portanto, "objetivos") e a dimensão subjetiva, a partir do conceito de intersubjetividade. A importante influência dos trabalhos de Csordas $(1994,2008)$, dentre outros, vem fomentando uma linha de pesquisas sobre os processos de significação, como, por exemplo, os trabalhos de Alves e Rabelo (1998, 2004), autores representativos dessa tendência no Brasil. No âmbito dessas discussões, destaco três momentos importantes das redefinições conceituais: a crítica à proeminência do conceito de representação sobre o de prática social; as redefinições conceituais de pessoa, corpo e experiência a partir de uma abordagem não dualista; a ênfase no conceito de itinerário terapêutico.

O primeiro momento refere-se à crítica aos estudos centrados na investigação das representações sociais, que são numerosos e conformam uma tradição na antropologia da saúde. Embora o emprego desse conceito tenha sofrido algumas variações, parece consensual a ideia de que o seu uso indiscriminado fez dele uma meta-noção muito pouco problematizada (Canesqui 2003). Em artigo bastante conhecido, Herzlich (1991) defende o seu uso a partir da ênfase no caráter socialmente construído da doença, ultrapassando, assim, as fronteiras da concepção medicalizada. A investigação das representações como recurso interpretativo dos comportamentos sociais, inferindo-se a questão do sentido nesse esforço, tem como objetivo principal delinear as imagens produzidas no âmbito da sociedade que, longe de serem consensuais, constituem objeto de disputas entre diferentes grupos. Respondendo às críticas frequentemente dirigidas à utilização desse 
conceito, a autora enfatiza que o estudo das representações sociais não visa à predição das condutas individuais, mas antes à investigação dos códigos de significação que orientam as práticas, trabalho este que deve ser feito pelo pesquisador, na medida em que, para o nativo, as representações são percepções que não evidenciam o seu caráter socialmente construído.

Ainda que continue sendo largamente utilizado, a tradição francesa na qual se ancora o conceito de representação social não deixa de ser problematizada. Alves e Rabelo (1998) fazem uma crítica à proeminência das representações sobre as práticas na investigação dos processos de adoecimento. Isto porque as abordagens centradas no estudo das representações sociais tendem a reproduzir uma dicotomia clássica ao suporem a anterioridade daquelas sobre as práticas, o que reifica, no final das contas, uma abordagem que subsume as práticas à mera reprodução de significados subjacentes, ou seja, que já se encontrariam dados anteriormente à elaboração de significados no contexto mesmo da experiência do adoecer.

Como enfatizam os autores, é preciso uma redefinição das "relações entre pensamento e ação; consciência e corpo; cultura e individualidade" (1998:108), considerando-se que o fundamento dessas problematizações reside na própria crítica à dicotomia fundante entre abordagens objetivistas e subjetivistas. O redirecionamento do significado da ação social proposto visa justamente eliminar o pressuposto de que ela se desenrola a partir de "determinantes" externos para localizar a investigação no seu caráter situacional e processual. Assim, a produção dos significados passa a ser investigada no âmbito mesmo do desenrolar da ação, tida como "criadora" e não apenas como "atualizadora" de sentido.

No segundo momento, de problematização de conceitos-chave, destaca-se a relevância do contexto em que as significações são construídas e que pode ser verificada na ênfase concedida à dimensão das práticas sociais, sendo no curso da ação social que se elaboram as referências culturais. Para a compreensão desse processo apresento as discussões em separado:

a) Redefinição do conceito de sujeito: A concepção de um sujeito reflexivo, cuja identidade é compreendida por meio da ideia de permanência, vem sendo substituída por uma perspectiva mais dinâmica, afinada com uma problematização da subjetividade. O que se propõe é o abandono de uma concepção de sujeito enquanto um núcleo autônomo para considerar “[...] o caráter imediatamente relacional e irremediavelmente contingente de nossas identidades e historicidades como indivíduos e como grupos" (Ayres 2001:65). Assim, nesse paradigma observase uma revisão das abordagens centradas no "eu" como 
dimensão reflexiva sem considerar a sua mediação com o corpo, instância pré-reflexiva de produção de conhecimento. Como desdobramento dessa concepção mediada do sujeito, desenvolve-se uma crítica da dicotomia entre projeto (como ação racional) e hábito (como resistência corporal), reconhecendo-se essas dimensões enquanto relação dinâmica. O hábito passa a ser compreendido como um saber radicado no corpo, que oferece uma forma de engajamento do sujeito em qualquer contexto de ação, inclusive naqueles que mobilizam a intencionalidade de um projeto racional. Por outro lado, os projetos de ação nunca são exatamente claros, mas, antes, imagens e possibilidades que são mediadas pelo hábito, sendo este compreendido como fruto de um projeto anterior, no qual se processou um engajamento corporal. Projeto e hábito, dessa forma, devem ser compreendidos como dimensões não excludentes da ação, mas que se imbricam continuamente (Alves \& Rabelo 1998).

b) O saber radicado no corpo: o corpo passa a ser considerado "não apenas como a matéria em que se inscreve o texto da cultura [...] mas também como produtor de sentido, lócus em que se articulam formas de conhecimento e intervenção sobre o mundo" (Rabelo \& Alves 2004:175). A partir da abordagem fenomenológica, que estabelece uma relação entre consciência e mundo, a dimensão pré-reflexiva é fundamentalmente considerada através do corpo, percebido, então, como "corpo vivido". Não se deve operar, portanto, uma cisão entre o saber radicado no corpo (que nas abordagens dualistas consideramna como uma experiência do sensível, sem a produção de sentido) e as representações sociais tidas como a expressão da cultura, da cognição do mundo.

c) A centralidade da experiência: Nas abordagens tradicionais, a singularidade do evento não é pensada como produtor de sentido, sendo desconsiderada em favor da investigação dos "padrões", recorrentes, que subjazem à especificidade dos contextos nos quais se desenrolam as práticas. Inversamente, o conceito de experiência ganha centralidade heurística na perspectiva aqui observada pelo fato de que nele se entrecruzam dimensões que nas abordagens objetivistas são tratadas enquanto dicotomias conceituais: "O conceito de experiência visa justamente superar a cisão entre sensação e 
sentido, percepção e cognição, natureza e cultura, apontando para uma cumplicidade originária com o mundo e com os outros que é condição para que algo possa ser posteriormente representado" (Alves \& Rabelo 2004:193). A partir da prioridade concedida à situação em que se processam os significados, a experiência aparece como um "ponto de partida para a compreensão da enfermidade" (Alves 1993:268). Aqui a experiência deve ser considerada não apenas como a emanação de sensações corporais difusas: ela precisa ser organizada numa totalidade significativa para o agente, e esse processo é logrado no contexto da intersubjetividade da vida cotidiana. A importância crescente do conceito de experiência compreende também uma dimensão processual (e não apenas o aspecto da mediação, eliminando dicotomias), o que significa considerar as hesitações, as indefinições e as mudanças de escolhas no curso de uma experiência de enfermidade. ${ }^{6}$

Por fim, o terceiro momento que gostaria de destacar é o conceito de itinerário terapêutico, que procura explicitar a dimensão de transitoriedade, como sugere Alves: "A produção de significados é resultante não de um instante pontual do 'eu', mas de toda uma história do 'eu'" (1993:269). Em sociedades como as nossas, marcadas fortemente por uma hegemonia do modelo biomédico, por um lado, e por uma pluralidade de sistemas terapêuticos concorrenciais e/ou complementares ao modelo hegemônico, por outro, é necessário, para se compreender o processo de significação da experiência da enfermidade, considerar sua dimensão temporal. Essa temporalidade compreende não apenas a ideia de que há um desenrolar do significado que implica alterações de escolhas, mas também a percepção de que nesse processo nem sempre se observam sínteses bem elaboradas de adesão a um ou outro tratamento; pelo contrário, muitas vezes são as indefinições e as sínteses parciais e provisórias que conferem a tônica de uma trajetória (Rabelo et al. 1999).

Numa análise crítica aos trabalhos que abordam a questão do itinerário terapêutico, Alves e Souza argumentam acerca da inadequação dessas abordagens por se fundamentarem em premissas explicativas:

Assim, a interpretação das ações que as pessoas desenvolvem para lidar com suas aflições é subsumida a uma lógica meramente explicativa, característica de um determinado modelo do conhecimento científico. Acreditamos que considerar a interpretação e a explicação como equivalentes e intercambiáveis acarreta sérios problemas epistemológicos que objetivam explicar as ações de indivíduos ou grupos sociais (1999:130). 
Na medida em que os modelos explicativos fundamentam-se na busca de significados, considerando-os como subjacentes à experiência social, esses modelos não podem captar de forma adequada as elaborações de sentido que são processadas nos contextos, sempre marcados pela intencionalidade, circunstancialidade e dialogia. A explicação deve, assim, ser considerada como um segundo momento que só ocorre quando a abordagem compreensiva se processou.

"Descer", portanto, ao nível das experiências sociais compreende, como sugerem Alves e Souza no texto citado, o reconhecimento de algumas considerações teórico-metodológicas: a) a escolha e a avaliação dos tratamentos no curso da enfermidade não estão condicionadas por uma única estrutura cognitiva, mas, muito pelo contrário, pautam-se pelo entrecruzamento de diferentes tipos de conhecimentos formulados dentro de um campo de possibilidades; b) o processo de escolhas terapêuticas implica o compartilhamento de variadas possibilidades oriundas de um "estoque de conhecimentos" adquirido ao longo de uma trajetória de vida. Estas duas considerações buscam delinear um quadro de referência nos estudos sobre itinerário terapêutico, considerando-o como um conjunto de atos que se desenrolam em diferentes "níveis" implicando planos, estratégias e projetos no tratamento da enfermidade, "níveis" estes que não compõem um esquema predeterminado. Dessa forma, nos processos de escolha e decisão intervêm atos, discursos, imagens que vão compor, dentro do campo de possibilidades dos agentes sociais, as "possibilidades problemáticas" que não são preestabelecidas, mas decorrentes das virtualidades implicadas na experiência.

Numa defesa à abordagem centrada na experiência, pode-se considerar que ela não pretende reeditar falsas dicotomias decorrentes da opção pelas teorias da ação em contraste com as teorias da estrutura. Procura, antes, compreender a singularidade, a provisoriedade e a ação criadora de sentido sempre implicadas nos itinerários terapêuticos.

Inspirando-me em Latour, penso, no entanto, que reconhecer a incerteza oriunda da complexidade envolvida nesses processos de ação pode reeditar uma nova dicotomia que confina a imprevisibilidade exclusivamente ao domínio da intencionalidade humana (intersubjetiva), deixando de fora a contingencialidade que atravessa a configuração do social. Recusando esse caminho, Latour (2006) aponta as incertezas que perpassam o social, ao mesmo tempo em que o constitui:

Ainda que eles [os fenomenólogos] tenham tido razão de insistir nas incertezas, eles se equivocaram no momento em que quiseram localizar as suas fontes. Os humanos capazes de intenção, as pessoas dotadas de intimidade, as almas dotadas de individualidade não são os únicos agentes interpretativos num mundo de fatos indiscutíveis e privados de toda significação (:353, tradução minha). 
O conceito de experiência, central nas novas abordagens da antropologia da saúde, pode ser pensado à luz das contribuições mais recentes de Latour (2006), quando argumenta sobre a necessidade de perseguirmos as redes de mediadores na construção do social. Segundo o autor, um problema implicado na concepção fenomenológica de experiência reside no reconhecimento de que os processos de significação são elaborados somente nas relações face a face, suspeitando de toda e qualquer proeminência do contexto (considerado como a instância que constrange a ação), o que tornaria a ação mera repetição de estruturas que lhe são anteriores. Recusando também o contexto como uma instância hierarquicamente anterior e determinante ao curso da ação, Latour (2006:353) constrói outra linha de investigação, recusando a exclusividade heurística das abordagens centradas nas relações face a face, pois justamente não reconhecem que as fontes da incerteza se encontram distribuídas por uma extensão muito mais ampla. Assim, penso que a potencialidade do conceito de experiência poderia ser mais bem aproveitada se situada no processo de confecção das redes de mediadores, ou seja, recusando planos explicativos subjacentes à ação, mas ao mesmo tempo alargando o campo de visão para além das abordagens micro, na medida em que a extensão das redes produz muitas pequenas, mas fundamentais diferenças no social que continuamente se redesenha.

Parece-me, então, que um deslocamento pode ser sugerido na abordagem do itinerário terapêutico, não mais enfocando exclusivamente os processos intersubjetivos - impliquem estes decisões, hesitações, expectativas, desejos, imagens - mas um leque bem mais amplo de mediações que caracterizariam toda e qualquer atividade do mundo. Nos mundos possíveis que emergem desta perspectiva, a criatividade não constitui um atributo situado no âmbito da cognição humana, mas configuraria uma potencialidade inscrita na ontologia dos mundos ou, como diria Ingold, atributos na forma de skills, intrinsecamente articulados à feitura dos corpos.

\section{Dos itinerários aos agenciamentos terapêuticos}

O itinerário terapêutico, sendo processual, comporta hesitações, indefinições e mudanças de escolha no curso de uma experiência de enfermidade, envolvendo inúmeras mediações que se desenrolam numa temporalidade específica. Mas, se descentrarmos o sujeito e redistribuirmos as incertezas ao longo do fluxo de mediações que perfazem o social, pode-se sugerir uma nova paisagem de configuração do espaço público de mediações terapêuticas: espaço de multiplicidades, atravessado por associações rizomáticas que desafiam a todo momento os dispositivos de hierarquização e controle envolvidos nos processos de territorialização (Deleuze \& Guatarri 1997). 
Se a problematização das dualidades no paradigma da experiência não redistribui, como vimos, as incertezas através do social, parece-me necessário realizar um segundo deslocamento: compreender os itinerários enquanto agenciamentos terapêuticos. A contingencialidade que caracteriza a experiência do adoecer, marcada por indecisões, dilemas e expectativas quanto ao desenrolar do processo de cura, coloca em evidência a subjetivação aí implicada. Mas, uma vez que ela não está "dada" (anteriormente à experiência) e nem se encontra "desencarnada" (sendo elaborada no curso mesmo do processo), pode-se considerá-la enquanto um agenciamento.

Contrariamente à noção de que nós somos nossos corpos, nós fazemos nossos corpos. A partir desse deslocamento sugerido por Mol e Law (2004) é possível problematizar as relações entre subjetividade, emoção e corpo considerando as diferenças intensivas ou devires apontados no início deste trabalho. Recusando a démarche tradicional que opõe emoção e afeto (ausência de significação) ao conhecimento (produção reflexiva), essas "dimensões" encontram-se necessariamente implicadas nos processos de ação. Esta ideia pode ser desenvolvida através do conceito deleuziano de agenciamento, que interdita qualquer dualismo (como desejo e instituição, individual e coletivo): as expressividades e seus regimes de enunciação são atravessados por movimentos de territorialização (molares) e de desterritorialização (moleculares). ${ }^{7}$ Assim, os agenciamentos concretos (e o indivíduo se constitui num agenciamento) são necessariamente instáveis, já que processam em graus variáveis esses dois movimentos, e neles as "afecções" não são tomadas como "ruídos" desestabilizadores das ações, mas possibilidades de desterritorialização de agenciamentos estabilizados, redefinindo corpos e enunciados.

Contornando as abordagens fenomenológicas da corporeidade, em recente trabalho Rabelo (2013) aponta as contribuições de Latour, Mol e outros que procuram justamente uma nova conceituação dos limites e das evidências do corpo, fazendo com que este emerja na manipulação das práticas e não ao contrário, como um pressuposto disciplinar ou interdisciplinar. Abordando as atividades sobre a comida e o comer desenvolvidas no contexto ritual do candomblé, na narrativa de Rabelo vêm à tona diferentes possibilidades conceituais da corporeidade em processo. No ebó, temos um corpo de densidade tátil, cuja sensorialidade não se dirige ao exterior, mas se deixa impregnar pelo afrouxamento das fronteiras entre corpo e comida. A comida manipulada no ritual do bori propicia outra metamorfose do corpo, destacando a cabeça e ao mesmo tempo projetando-a para fora, na bacia ritual (ibá ori). "Comer, conclui a autora, é, assim, uma atividade distribuída entre muitos agentes. Entre muitos locais" (:9). Estas características também são observadas no último ritual analisado, o assentamento de orixá: também aqui temos uma redistribuição dos fluxos da comida. 
Nesse exercício sugestivo, a autora nos convida a explorar novas possibilidades de investigação da corporeidade, cuja garantia não está dada de antemão, mas deve ser perseguida nas práticas ou nos rastros, como sugere Latour. Por outro lado, indica o que deve ser evitado: o "recurso fácil a entidades genéricas que se supõe preceder e explicar essas práticas - o corpo, o habitus" (2013:14). A experiência da enfermidade, acessível através dos agenciamentos terapêuticos, também aponta para a proliferação de mediações (e suas fontes de incerteza) que atravessam extensas redes de cuidado, como é o caso da Estratégia Saúde da Família (ESF). Mas em que medida se potencializam novos dilemas na prática do cuidado nesse contexto terapêutico? E como o conceito de agenciamento se torna produtivo para a investigação dessas mediações? Na próxima seção apresento algumas pistas sobre a potencialidade do agenciamento para compreender três dimensões da ESF: o território, o usuário e o corpo.

\section{Agenciamentos terapêuticos no âmbito da ESF}

A estruturação da ESF está ancorada numa perspectiva de cuidado que processa um estriamento específico na territorialização do seu campo de ação. ${ }^{8}$ Mas esse estriamento não leva em consideração que esses espaços se encontram atravessados por redes intersticiais (rizomáticas) de cuidado: ${ }^{9}$ é o espaço liso que se deixa estriar, mas ao mesmo tempo não deixa de produzir linhas de desterritorialização, linhas de fuga (as redes intersticiais construídas no cotidiano dos "usuários" do sistema) que interagem com o estriamento do espaço realizado na ESF. ${ }^{10}$ Essas redes intersticiais implicam agenciamentos do cuidado que se diferenciam (por conflitos, tensões e outras formas de desacordo, mas também por colaborações) do cuidado dos profissionais de saúde, apontando para a diversidade e a heterogeneidade dos mediadores envolvidos nesses processos.

Levar a sério a heterogeneidade das redes de cuidado pode ser produtivo para se perseguirem as controvérsias sobre as extensões do "terapêutico" nos processos de cuidado. No já citado trabalho de Kelly sobre os Yanomani, os desafios das equipes de saúde (com agentes de saúde yanomami) estendem-se para as situações das visitas médicas, que são mais do que simplesmente visitas, evidenciando, assim, as diferentes expectativas de médicos e nativos: fazem-se muitas outras coisas além do tratar de assuntos terapêuticos, como visitar parentes, circular objetos e notícias etc. Dessa forma, a produção de convenções e os agenciamentos implicados nessas tarefas são diferenciados entre os sujeitos que fazem o cuidado da saúde, 
disseminando-se para além do que é convencionalmente considerado como terapêutico. Para o autor, residiria nesses desacordos a maior fonte de tensões entre brancos e yanomami.

Assim, ao perseguirmos os agenciamentos terapêuticos (considerando que o "terapêutico" é objeto de controvérsia) nas pesquisas sobre a ESF, mais "coisas" (no sentido de Ingold 2012) ou mediadores heterogêneos (no sentido de Latour 2006) "aparecem": além de pessoas (usuários, equipes de saúde, terapeutas não oficiais, religiosos, vizinhos, família etc.), há objetos (medicamentos, instrumentos médicos, formulários, tecnologias de gestão, posto de saúde etc.), classes sociais, habitus, condicionantes de saúde etc. Mas é preciso ter em mente que as redes intersticiais de cuidado não "aparecem" como mais um objeto no mundo. Elas não são delimitáveis em algum sentido por sua autonomia em relação às redes de cuidado oficiais da ESF. As redes (oficiais e intersticiais, que se encontram imbricadas) constituem formas (ou calibragens) que nos permitem identificar e compreender os percursos, isto é, são recursos metodológicos (Latour 2006). Abrangem as maneiras pelas quais nós podemos perseguir a heterogeneidade dos cuidados em sua capilaridade ou paisagem rizomática.

A visibilização do trabalho das redes intersticiais operada pelo conceito de agenciamento terapêutico nos possibilita entender a prática dos profissionais de saúde em novos termos. Assim, embora do ponto de vista oficial essas redes não sejam consideradas, no trabalho cotidiano as equipes de saúde acabam por reconhecê-las, desencadeando situações ambíguas de convivência. Por outro lado, a emergência dessas redes também é propiciada pela filosofia da ESF que veicula novas formas de cuidado, mais descentralizadas em relação ao papel do médico, e que podem ser identificadas através de alguns indicadores:

a) A regulamentação da ESF, que procura superar a noção tradicional de cuidado fragmentado, assentado na divisão técnica do trabalho em saúde. Segundo a concepção oficial, seria preciso superar esse modelo segmentário, propondo um novo paradigma em saúde ancorado na qualidade de vida. Um modelo no qual o indivíduo se encontra situado na relação entre família e comunidade (substitutivo da rede básica tradicional), de cobertura universal, com o compromisso de assumir o desafio do princípio da equidade. Sua estratégia prevê um contato maior dos profissionais de saúde com as famílias, com vistas à humanização do atendimento, propondo a criação de uma relação de confiança entre a equipe de saúde e a população.

b) A ressignificação do "acolhimento" para a otimização do fluxo de atendimento nas Unidades Básicas de Saúde (UBS). O modelo de eficiência no acolhimento propagado pela ESF não se restringe à rapidez no atendi- 
mento, mas compreende que no espaço da UBS a atenção ao usuário não se limita a uma triagem realizada segundo critérios técnicos, mas também pela sensibilidade do cuidado.

c) A extensão do cuidado para além dos limites da UBS. Como a "demanda espontânea" é bem maior que a capacidade de atendimento médico, esse descompasso configura um ponto propiciador de enormes tensões entre as equipes da ESF e a comunidade assistida. Por outro lado, é possível sugerir que essa assimetria decorre, em alguma medida, do próprio sucesso do trabalho das equipes de saúde que potencializam as mediações do cuidado, visibilizando novos agenciamentos para velhos problemas (Tavares et al. 2015). Além do atendimento emergencial, os profissionais realizam seu trabalho através de diferentes formas de atenção: "atendimentos programados" com grupos de risco (gestantes, hipertensos, diabéticos etc.), trabalho de mediação cotidiano dos agentes de saúde, ações educativas em saúde, programas assistenciais e de qualidade de vida, além da diversidade de ações que envolvem os imponderáveis das situações cotidianas das populações atendidas.

d) A heterogeneidade dos recursos terapêuticos utilizados. Além dos procedimentos médicos, verifica-se a valorização das tecnologias "leves", como a conversa, o acolhimento, a visita domiciliar e outros procedimentos que orientam para uma forma de cuidado em que possam estar presentes mediadores "inusitados", como, por exemplo, a "felicidade" (Ayres 2004).

Para se pensarem esses processos de desterritorialização como linhas de fuga possíveis, é preciso considerar seriamente a proliferação dos mediadores disseminados nos agenciamentos entre humanos e não humanos. É necessário, portanto, reconhecê-los em sua característica essencial: transformar processos acrescentando algo ao curso das ações. No âmbito da ESF não se pode denegar o seu papel, priorizando apenas aqueles considerados legítimos. Uma abordagem que siga essa orientação fica limitada à compreensão das intervenções realizadas pela equipe de saúde, considerando como periféricos outros processos que desencadeiam um leque muito amplo de afetações. Da mesma forma, mediadores não legítimos passariam ao largo da investigação, invisibilizados: é o caso, por exemplo, da miríade de espíritos da umbanda, do candomblé e do kardecismo; dos santos, das rezas e das promessas; dos chás e das receitas caseiras, para citar apenas alguns deles. Corre-se, assim, o risco de considerar as terapêuticas populares ou religiosas como índices da tradição, imaginadas como sobrevivências ou exoticidades que persistem nas margens ou que se opõem aos processos de modernização.

Levar a sério o trabalho da mediação nos faz retornar à questão central do lugar ocupado pelo usuário nesse sistema de saúde. A rede de cuidado 
da ESF evidencia uma modificação na sua posição, afastando-o da passividade implicada na condição de "público-alvo". No entanto, essa nova condição do usuário nem sempre é reconhecida pelos profissionais de saúde (Crevelim \& Peduzzi 2005). Emergem desses desencontros situações de ambiguidade em que ao tempo em que se reconhece sua participação (do usuário), também se delegam aos "condicionantes sociais" um papel determinante. Em trabalho anterior com colaboradores (Bonet et al. 2009), buscamos produzir um deslocamento em torno da ideia de público-alvo e usuário-centrado para a de "situação-centrada", indicando uma valorização dos processos ao invés das "entidades" (profissionais de saúde, usuários e outros) para se compreenderem as dinâmicas do cuidado em ação. Penso ser justamente isto que o conceito de agenciamento terapêutico possibilita fazer: menos objetos, mais processos.

Além disso, se pensarmos que diferentes conhecimentos e "regimes de enunciação" (Latour 2004) entrecruzam-se nas práticas de "cuidado", poderemos então problematizar a tessitura de relações processadas no âmbito da ESF como práticas de produção da verdade em que estamos todos implicados: profissionais de saúde, usuários e pesquisadores. O usuário interfere tanto quanto todos os demais profissionais de saúde nos processos de cuidado. Ele não é um objeto a que se destinam as políticas, mas ele ou ela interfere criativamente, reconfigurando, surpreendendo, problematizando, enfim, "trazendo o sistema à vida" (numa analogia com a feliz expressão de Ingold 2012), o que faz com que todos produzam interferências no curso dos acontecimentos. Se o usuário não é o fim ou o "alvo" do processo, precisamos persegui-los em situação, fazendo da nossa unidade de análise não o usuário-centrado, mas a situação-centrada. Apenas nas situações estão os desafios envolvidos no cotidiano dos profissionais e no futuro da ESF.

Por fim, a última dimensão a ser destacada no rendimento do conceito de agenciamento se refere ao descentramento do conceito biológico de corpo. No espaço terapêutico da ESF, as experiências da corporalidade não são reduzíveis às diferenças de crenças ou subjetividades. É o que apontam Bustamante e McCallum (2010) ao investigarem diferentes projetos de pessoa (no trabalho das autoras, em torno de decisões que envolvem a maternidade e o aleitamento), ancorados em experiências sociais específicas (e não apenas em intersubjetividades) e que produzem desencontros entre profissionais e usuários na ESF. Além disso, é preciso também levar em conta que as mediações terapêuticas se desenrolam em espaços heterogêneos e não apenas nas salas dos consultórios, intensificando a heterogeneidade do cuidado através dos muitos cuidadores no manuseio de corpos variados. 
A diversidade de competências nos "modos de fazer" conhecimentos e corpos atravessa a prática do cuidado e apresenta duas faces: através da diversificação dos cuidados (profissionais ou não) que atuam na ESF, por um lado, e pela "hibridização" das competências no âmbito do trabalho cotidiano dos profissionais, por outro. Em relação ao primeiro aspecto, observa-se, como dimensão mais visível desse processo, a "inclusão" de agentes populares, como, por exemplo, as parteiras, no cotidiano das equipes de saúde. Como aponta Fleischer (2006), longe de constituírem um grupo dotado de "conhecimentos tradicionais", ocupando uma fronteira de resistência à modernização, as parteiras apresentam dilemas atuais. A autora problematiza, assim, as abordagens que cristalizam comportamentos, técnicas e valores dessas profissionais, tidos como inadequados (para os céticos) ou autênticos (para os defensores), ao invés de pensá-las em relação com os outros profissionais (Fleischer 2006:39). Quanto ao segundo aspecto, pesquisadores têm chamado a atenção para as características da mediação (assimétrica) do agente de saúde. Devido à proximidade com o usuário e estimuladas pela vivência cotidiana na comunidade, as especificidades do seu trabalho fazem com que eles vivenciem mais intensamente, mas não exclusivamente, os problemas cotidianos da ESF (Nunes et al. 2002; Tavares et al. 2015).

Assim, investigar os agenciamentos construídos nas redes oficiais e intersticiais é central para que se possam compreender os dilemas envolvidos no trabalho das equipes da ESF. E isso porque estão disseminados em mediações do cuidado que operam em redes de calibragens variadas, marcadas por situações em que o "usuário" também é ativo, comportando diferentes conceituações do "terapêutico" em corpos variados. Através do agenciamento terapêutico é possível perseguir as mediações que são cotidianamente processadas dentro e fora das unidades básicas de saúde, "vasculhando" os rastros deixados ao longo do processo de cuidado em toda a sua extensão, seja nas situações de "proximidade" (relação médico-paciente; "curador"-paciente; "médico"-curador etc.), seja nas de "distanciamento" (processadas através de inúmeros mediadores de gerenciamento, técnicos, educacionais, de controle, entre outros).

\section{Conclusão:}

\section{sobre as possibilidades do agenciamento terapêutico}

Gostaria, nesse momento, de retomar alguns pontos já apresentados para jogá-los numa perspectiva de possibilidades futuras do conceito, problematizando os limites autoevidentes do sujeito (fenomenológico) e do corpo 
como referente universal (Latour 2008). Se, como sugere Latour (2006), é preciso ter cautela com o conceito de experiência, isto não significa dizer que seja necessária sua desabilitação, já que o rendimento que o conceito de agenciamento pode oferecer é justamente o da experiência que extravasa corporeidades biologizadas.

A filosofia empírica de Mol, abordada acima, explicita a intenção de apresentar uma etnografia transgressiva que, em vez de investigar diferentes perspectivas sobre o corpo, focaliza as práticas que fazem surgir (ou aparecer) ontologias variáveis ao invés de entidades singulares como "o" corpo. A etnografia da "feitura" de corpos e doenças compreende uma situação hospitalar em que, através do conceito de enactement, podem ser perseguidos os agenciamentos terapêuticos sem permanecer no território cativo dos trabalhos antropológicos centrados nas narrações e nas significações sobre corpos e emoções.

Essas ideias podem ser produtivas em diferentes situações de pesquisa em antropologia da saúde, desde ambientes hospitalares, passando por programas de saúde pública (como a ESF), até contextos religiosos. A potencialidade da investigação dos agenciamentos terapêuticos reside justamente na recusa em adiantar quais domínios seriam mais importantes ou decisivos para a compreensão da eficácia desses processos. Transformações em corpos, sujeitos, emoções, religiões, curas não configuram domínios preestabelecidos dos processos de ação, mas apresentam-se como virtualidades em qualquer agenciamento concreto. Além disso, vale observar também que uma característica que atravessa a diversidade terapêutica contemporânea refere-se à intensificação dos agenciamentos moleculares, mobilizando a desterritorialização nos processos de cura.

Nosso objeto da pesquisa deixa de ser epistemológico (não importa saber se as representações sobre a realidade são adequadas segundo critérios pré-definidos), para se situar na pragmática do processo. Mais especificamente, é central o conhecimento gerado pela interação e pela manipulação prática, os "objetos" não estando passivamente à espera de serem descobertos, mas aparecendo ou desaparecendo conforme as práticas através das quais eles são manipulados. Objetos variáveis, mundos múltiplos de corpos e curas, mas também de eficácias e de fundamentos. Trata-se, assim, da argumentação em torno de novas possibilidades etnográficas nas quais possamos acompanhar os processos (práticas) que fazem emergir a experiência da saúde e da doença, dos sujeitos e da corporeidade como resultados. 
Recebido em 17 de janeiro de 2017

Aprovado em 24 de abril de 2017

Fátima Tavares é professora associada do Departamento de Antropologia e da Pós-graduação em Antropologia da Universidade Federal da Bahia, Salvador/ BA, Brasil. E-mail: <fattavares@ufba.br>

\section{Notas}

1 Como acentua Viveiros de Castro a partir da leitura de Deleuze, "para determinar o que há a pensar como diferença intensiva antes que como substância extensiva" (2007:98). Os "devires", enquanto relações intensivas não podem constituir coisas nem "entidades" independentes das relações que são engendradas, ou como diz Latour (2006), constituem-se como modos de inscrição do mundo e não pontos de vista sobre o mesmo.

2 A ESF surge como um modelo substitutivo da rede básica tradicional, de cobertura universal, com o compromisso de assumir o desafio do princípio da equidade. Sua estratégia prevê um contato maior dos profissionais de saúde com as famílias, com vistas à humanização do atendimento. Propõe a criação de uma relação de confiança entre a equipe de saúde e a população. A proposta do programa é trabalhar com o princípio da vigilância à saúde, tendo como base programática a organização de atividades em um território definido, com o propósito de propiciar a resolução dos problemas identificados. A ESF foi pensada para reformular o contexto no qual são estabelecidas as relações entre os agentes de saúde e os usuários, procurando superar a percepção "tradicional" da prática médica que intervém sobre o indivíduo não situado, para reconhecer esse indivíduo enquanto situado no mundo.

3 A literatura antropológica das terras baixas sul-americanas é muito rica de etnografias que problematizam os processos de construção social dos corpos. Sobre esta questão, McCallum explicita no texto sua filiação ao conjunto de trabalhos que compreende os processos de fabricação dos corpos como não redutíveis aos dualismos ocidentais da biologia e da cultura.

4 Os sarode constituem uma dentre várias técnicas de cura. Além deles, temos a sucção (doenças graves e crônicas) e o sopro (doenças leves).

5 Segundo a autora, essa literatura transita entre duas possibilidades de compreensão do corpo: como entidade biológica ou natural, onde se alicerça a persona social e como mediador da vida social. 
6 Uma crítica dirigida a essa abordagem foi feita por Duarte (2003) em artigo no qual realiza uma revisão da linha de pesquisa nos estudos de saúde orientada pela hipótese metodológica da diferença entre os modelos relacionais de "pessoa" e de "indivíduo". Defendendo a viabilidade heurística dessa distinção, Duarte resenha várias contribuições dessa linha, explicitando a sua fundamentação mais abrangente: a) situa-se na vertente "universalista", com a elaboração de modelos interpretativos, mas ao mesmo tempo, como ele sugere, com uma tonalidade "romântica", já que reconhece a singularidade cultural; b) a "preeminência da significação sobre a prática na dinâmica da interpretação sociológica" (:179). Embora reconheça a importância dessa abordagem, não me detenho, neste trabalho, nos detalhes dessa crítica, pois meu foco situa-se nas abordagens que priorizam as práticas.

7 Sobre os conceitos de territorialização e desterritorialização, ver Deleuze e Guatarri (1997), especialmente o cap. 14: "1440 - O liso e o estriado". Sobre a relação desses conceitos com os polos molar e molecular dos agenciamentos, ver verbete "Agenciamento", em Zourabichvili (2004).

8 Articulado aos conceitos de territorialização e desterritorialização, podem ser evocados os conceitos de espaço liso e estriado, propostos por Deleuze e Guatarri (1997).

9 Em pesquisas anteriores (Bonet \& Tavares 2006, 2007, 2008) já foi indicado ser preciso considerar a coexistência de redes de cuidado à saúde que atravessam a territorialização promovida pela ESF. Uma primeira rede seria delimitada pela territorialização que a ESF estabelece na comunidade através do cadastro da população residente no âmbito do trabalho de uma equipe de saúde. Uma segunda rede se refere a cada unidade de cadastro, quer dizer, às unidades familiares. Sobre estas duas redes se realizam as intervenções de cuidado terapêutico da ESF. Mas essa estruturação da ESF tem que conviver na prática com outras mediações que não apenas a rede comunitária mais ampla e a rede das relações familiares.

10 Bonet e Tavares (2006) já mostraram a importância do reconhecimento da relação entre a ação da ESF e a condição da vizinhança e da família como redes de apoio. 


\section{Referências bibliográficas}

ALVES, Paulo C. \& SOUZA, Iara Maria A. 1999. "Escolha e avaliação de tratamento para problemas de saúde: considerações sobre o itinerário terapêutico". In: M.C. Rabelo; P.C. Alves \& I.M. Souza (orgs.), Experiência de doença e narrativa. Rio de Janeiro: Ed. Fiocruz. pp. 125-138.

ALVES, Paulo César. 1993. "A experiência da enfermidade: considerações teóricas". Cadernos de Saúde Pública, 9(3):263-271.

ALVES, Paulo César \& RABELO, Mirian C. 1998. "Repensando os estudos sobre representações e práticas em saúde/doença". In: P. C. Alves, M. C. Rabelo (orgs.), Antropologia da saúde: traçando identidade e explorando fronteiras. Rio de Janeiro: Ed. Fiocruz/ Ed. Relume-Dumará. pp. 107-122.

. 2004. "Corpo, experiência e cultura". In: A. Leibing (org.), Tecnologias do corpo. Uma antropologia das medicinas no Brasil. Rio de Janeiro: Nau Editora. pp. 175-200.

AUGÉ, M. 1984. "Ordre biologique, ordre social: la maladie como forme élémentaire de l'événement". In: $\mathrm{M}$. Augé \& C. Herzlich (eds.), Le sens du mal. Paris: Editions des Archives Contemporaines. pp. 35-92.

AYRES, José Ricardo. 2004. "O cuidado, os modos de ser (do) humano e as práticas de saúde". Saúde e Sociedade, 13(3):16-29.

. 2001. "Sujeito, intersubjetividade e práticas de saúde". Ciência \& Saúde Coletiva, 6(1):63-72.

BONET, Octávio \& TAVARES, Fátima. 2006. "Redes em redes: dimensões intersticiais no sistema de cuidados à saúde". In: R. Pinheiro \& R. A. Mattos (orgs.), Gestão em redes. Práticas de avaliação, formação e participação na saúde. Rio de Janeiro: Cepesc. pp. 385-400.

. 2007. "O cuidado como metáfora nas redes de prática terapêutica". In: R. Pinheiro \& R. A. Mattos (orgs.), Razões públicas para a integralidade em saúde: o cuidado como valor. Rio de Janeiro: Cepesc. pp. 263-278.

. 2008. "O usuário como mediador. Em busca de uma perspectiva 'ecológica' sobre os condicionantes sociais da saúde". In: Roseni Pinheiro \& Ruben Mattos (orgs.), Cuidar do cuidado: responsabilidade com a integralidade das ações de saúde. Rio de Janeiro, Cepesc/ IMS/UERJ/ ABRASCO. pp. 191-212.

BONET, Octávio; TAVARES, Fátima; CAMPOS, Estela Márcia Saraiva; TEIXEIRA, Maria Teresa Bustamante; RODRGUES, Michelle G. 2009. "Situação -centrada, rede e itinerário terapêutico: o trabalho dos mediadores". In: R. Pinheiro \& P. H. Martins (orgs.), Avaliação em saúde na perspectiva do usuário: abordagem multicêntrica. Rio de Janeiro: Cepesc - IMS/UERJ; Recife: Editora Universitária UFPE; São Paulo, ABRASCO. pp. 241-250.

BUSTAMANTE, Vania \& MCCALLUM, Cecilia Anne. 2010. "O cuidado de grávidas e bebês no contexto do Programa de Saúde da Família: um estudo etnográfico". Interface: Comunic., Saúde, Educ., 14(34): pp. 607-618.

CANESQUI, Ana Maria. 2003. "Os estudos de antropologia da saúde/doença no Brasil na década de 1990". Ciência \& Saúde Coletiva, 8(1):109-124.

CAROZZI, Maria Julia. 2002. "Crencias: lo que no es cuerpo para las ciencias sociales de la religión". Religião \& Sociedade, 22(1):77-92. 
CREVELIM, Maria Angélica \& PEDUZZI, Marina. 2005. "A participação da comunidade na equipe de saúde da família. Como estabelecer um projeto comum entre trabalhadores e usuários?". Ciência \& Saúde Coletiva, 10(2):323-331.

CSORDAS, Thomas. 2008. Corpo, significado, cura. Porto Alegre: Editora UFRGS.

. (org.). 1994. Embodiment and experience. The existencial ground of culture and self. Cambridge: Cambridge University Press.

DELEUZE, Gilles \& GUATARRI, Felix. 1997. Mil Platôs. Vol. 5. São Paulo: Ed. 34.

DUARTE, Luiz Fernando Dias. 2003. "Indivíduo e pessoa na experiência da saúde e da doença". Ciência \& Saúde Coletiva, 8(1):173-183.

FAVRET-SAADA, Jeanne. 2001. Les mots, la mort, les sorts. Paris: Gallimard.

FLEISCHER, Soraya. 2006. Parteiras, buchudas e aperreios. Uma etnografia do atendimento obstétrico não oficial na cidade de Melgaço, Pará. Tese de Doutorado em Antropologia, Universidade Federal de Rio Grande do Sul (UFRGS).

HERZLICH, Claudine. 1991. "A problemática da representação social e sua utilidade no campo da doença". PHYSIS-Revista de Saúde Coletiva, 1(2):26-36.

INGOLD, Tim. 2000. The perception of the environment. Essays on livelihood, dwelling and skill. London: Routledge.

.2012. "Trazendo as coisas de volta à vida: emaranhados criativos num mundo de materiais". Horizontes Antropológicos, 18(37):25-44.

KELLY, José Antônio. 2005. "Notas para uma teoria do 'virar branco'". Mana, 11(1):201-234 .
KLEINMAN, Arthur. "Some issues for a comparative study of medical healing". International Journal of Social Psychiatry, 19(3):159-165.

LATOUR, Bruno. 2008. "Como falar do corpo? A dimensão normativa dos estudos sobre ciência". In: João Nunes \& Ricardo Roque (orgs.), Objectos impuros: experiências em estudos sobre a ciência. Porto: Edições Afrontamento. pp. 39-61.

2006. Changer de société. Refaire de la sociologie. Paris: Éditions la Découverte. . 2004. "Não congelarás a imagem", ou: como não desentender o debate ciência-religião". Mana. Estudos de Antropologia Social, 10(2):349-376. . 2001. A esperanza de Pandora. Bauru, SP: Edeusc.

LANGDON, Ester. 2014. "Os diálogos da antropologia com a saúde: contribuições para as políticas públicas". Ciências \& Saúde Coletiva, 19(4):1019-1029.

MOL, Annemarie. 2003. The body multiple: ontology in medical practice. Durham, NC: Duke University Press. MOL, Annemarie \& LAW, John. 2004. "Embodied action, enacted bodies. The example of hypoglycaemia" (on-line papers). Center for Science Studies Lancaster University. Disponível em: http://doc.utwente.nl/48819/1/ Hypo39.pdf. Acesso em: 26 abr. 2017.

MC CALLUM, Cecilia. 1998. "O corpo que sabe. Da epistemologia kaxinawá para uma antropologia médica das terras baixas sul-americanas". In: P. C. Alves \& M. C. Rabelo (orgs.), Antropologia da saúde, traçando identidade e explorando fronteiras. Rio de Janeiro: Editora Fiocruz/ Editora Relume Dumará. pp. 215-245.

MONTERO, Paula. 2006. "Religião, pluralismo e esfera pública no Brasil". Novos Estudos, 74:47-65. 
NUNES, Mônica de Oliveira; TRAD, Leny Bonfim; ALMEIDA, Bethânia de Araújo; HOMEM, Carolina Ramos; MELO, Marise Claudia I. de C . 2002. "O agente comunitário de saúde: construção da identidade desse personagem híbrido e polifônico". Cadernos de Saúde Pública, 18 (6): 1639-1646.

RABELO, Mirian Cristina et al. 2002. "Comparando experiências de aflição e tratamento no candomblé, pentecostalismo e espiritismo". Religião \& Sociedade, 22(1):93-122.

RABELO, Míriam Cristina M.; CUNHA, Litza A.; SCHAEPPI, Paula B. 1999. "Religião, imagens e experiência de aflição: alguns elementos para reflexão". In: Mirian C. Rabelo; P. C. Alves; I. M. Souza (orgs.). Experiência de doença e narrativa. Rio de Janeiro: Ed FIOCRUZ. pp. 229-261. . 2013. "Corpos e espaços nas práticas de comida do candomblé". Trabalho apresentado na XVII Jornadas sobre Alternativas Religiosas na América Latina, Mesa Redonda: Religião e Corporeidade. Porto Alegre: UFRGS. Mimeo.

RENSHAW, John. 2006. "A 'eficácia simbólica' revisitada. Cantos de cura Ayoreo". Revista de Antropologia, 49(1):393-427.

SEEGER, Anthony; DA MATTA, Roberto; VIVEIROS DE CASTRO, Eduardo. 1979. "A construção da pessoa nas sociedades indígenas brasileiras". Boletim do Museu Nacional, 32:2-19.
STRATHERN, Marilyn. 2006. O gênero da dádiva. Campinas, SP: Ed. Unicamp.

TAVARES, Fátima. 2006. "Usos e significados da terapêutica no contexto religioso". Religião e Sociedade, 26(2):187-199.

TAVARES, Fátima; CAROSO, Carlos \& SANTANA, Carolina. 2015. "Mediações do cuidado no âmbito do Programa Saúde da Família em Itaparica, Brasil". Etnográfica. Revista do Centro em Rede de Investigação em Antropologia, 19(3):489-513.

VIVEIROS DE CASTRO, Eduardo. 2008. "Se tudo é humano, então tudo é perigoso". In: R. Sztutman (org.), Eduardo Viveiros de Castro. Rio de Janeiro: Beco do Azougue. pp. 86-113. . "O nativo relativo". Mana, 2002, 8.1: 113-148.

. 2007. "Filiação intensiva e aliança demoníaca". Novos Estudos, 77:91126.

. 1987. "A fabricação do corpo na sociedade xinguana". In: João Pacheco Oliveira Filho (org.), Sociedades indígenas \& indigenismo no Brasil. Rio de Janeiro: Marco Zero. pp. 31-42.

WAGNER, Roy. 2010. A invenção da cultura. São Paulo: Cosac Naify.

ZOURABICHVILI, François. 2004. O vocabulário de Deleuze. Trad. André Telles. Rio de Janeiro. Disponível em: $<$ http://escolanomade.org/wp-content/downloads/deleuze-vocabulario-francois-zourabichvili.pdf $>$. Acesso em: 17/01/2017. 
REDISCUTINDO CONCEITOS NA

ANTROPOLOGIA DA SAÚDE: NOTAS

SOBRE OS AGENCIAMENTOS

TERAPÊUTICOS

\section{Resumo}

Este artigo questiona o uso de alguns conceitos teóricos na investigação dos processos de cura na contemporaneidade. O argumento principal que apresento é que os modelos interpretativos ancorados em dicotomias e classificações podem "engessar" conceitos como corpo, sujeito e experiência, pouco auxiliando a investigação e compreensão das mediações e eficácias mobilizadas nos contextos terapêuticos. Para dar suporte a este argumento, começo apresentando alguns dilemas em torno da própria constituição do objeto da antropologia do corpo e da saúde, nas "escolhas" terapêuticas em situações etnográficas de populações indígenas e em contextos de adesão religiosa; a seguir, passo pela crítica de alguns conceitos-chave daquele campo da antropologia; ao final, proponho o conceito de agenciamento terapêutico como abordagem alternativa às discussões sobre experiência e itinerário terapêuticos.

Palavras-chave: corpo, experiência, itinerário terapêutico, agenciamento
REVISITING CONCEPTS IN THE

ANTHROPOLOGY OF HEALTH: NOTES ON THERAPEUTIC AGENCIES

\section{Abstract}

This article raises questions about the use of certain theoretical concepts in the investigation of healing processes in the contemporary world. Its main argument is that interpretative models based on dichotomies and classifications that freeze concepts like 'body', 'subject' and 'experience' are unhelpful in investigations of the mediations of therapeutic experiments. In support of this argument, I discuss some dilemmas concerning the very constitution of the object of an anthropology of the body and health and of the therapeutic choices in ethnographic situations involving indigenous peoples and in contexts of religious adherence. I then criticize some key concepts in anthropology of the body and health. Finally, I propose the concept of 'therapeutic agency' as an alternative approach to the discussions of therapeutic itinerary and experience. Keywords: body, experience, therapeutic itinerary, therapeutic agency. 
REDISCUTIENDO LOS CONCEPTOS DE LA ANTROPOLOGÍA DE LA

SALUD: NOTAS SOBRE LOS AGENCIAM IENTOS TERAPÉUTICOS

\section{Resumen}

En este artículo se cuestiona el uso de algunos conceptos teóricos en la investigación de los procesos de curación en los tiempos contemporáneos. El argumento principal que presento es que los modelos interpretativos basados en dicotomías y clasificaciones en que se congelan los conceptos de cuerpo, sujeto y experiencia poco ayudan en la investigación y comprensión de las mediaciones y eficacias movilizadas en contextos terapéuticos.
Para apoyar este argumento, comienzo a presentar algunos dilemas alrededor de la constitución misma de los objetos de la antropología del cuerpo y la salud, en las "opciones" terapéuticas en situaciones etnográficas de pueblos indígenas y en contextos de afiliación religiosa; luego paso por la crítica de algunos conceptos clave de ese campo de la antropología, para finalmente, proponer el concepto del agenciamiento terapéutico como un enfoque alternativo para las discusiones acerca de itinerario y experiencia terapéuticos.

Palabras clave: cuerpo, experiencia, itinerario terapéutico, agenciamiento terapéutico. 